\title{
Scientific production on falls and deaths among elderly persons: a bibliometric analysis
}

\author{
Denise Guerra Wingerter' \\ Ulicélia Nascimento de Azevedo ${ }^{\top}$ \\ Andrea Márcia Marcaccini² \\ Maria do Socorro Costa Feitosa Alves' \\ Maria Ângela Fernandes Ferreira? \\ Luana Kelle Batista Moura'
}

\section{Abstract}

Objective: To map international scientific production on falls and deaths among the elderly. Method: A bibliometric study of academic papers was carried out in the ISI Web of Knowledge/Web of Science ${ }^{\mathrm{TM}}$. The search terms "elderly*", "fall*" and "death*" were used for studies between 1990 and 2016. Articles from events or those still in the editing process and studies in the form of "conference proceedings", "editorial material" and "letters" were excluded, with only finished studies and complete "articles" and "reviews" considered. Results: After applying the refinement filters, 668 articles were identified during the 26 year evaluation period, published in 364 different journals indexed to the database in question. These were written by 2,958 authors with links to 1131 research institutions located in 63 countries. The articles included 22,093 references, with an average of approximately 33 references per study. Conclusion: The articles on falls and deaths among the elderly emphasize the need for more specific studies on the subject and its potential for exploration in future research. This study revealed the need for this issue to be discussed in the training of health professionals, as it represents an opportunity to deconstruct and reconstruct concepts and values that are established throughout the life of individuals, such as care related to the avoidability of falls, to improve the quality of life of this population.
Keywords: Health of the Elderly. Accidental Falls. Mortality. Bibliometrics.

\footnotetext{
Universidade Federal do Rio Grande do Norte, Centro de Ciências da Saúde, Programa de Pós-graduação em Saúde Coletiva. Natal, Rio Grande do Norte, Brasil.

2 Universidade de Ribeirão Preto, Faculdade de Odontologia de Ribeirão Preto, Programa de Pós-graduação em Odontologia. Ribeirão Preto, São Paulo, Brasil.
} 


\section{INTRODUCTION}

Population aging is natural and universal phenomenon, and can result in individuals reducing their normal functional capacities, culminating in recurrent illnesses and accidents. In Brazil, the numbers of elderly persons are increasing, reflecting a real and characteristic panorama of demographic transition and a reduction in mortality and fertility rates ${ }^{1}$.This profile raises questions and challenges that require new studies and reflections in order to meet the demands of this age group. Aspects related to comorbidities and the disorders that arise with age are therefore of particular importance, notably postural instability and falls, geriatric syndromes that encompass the alterations relevant to the elderly person, and thus representing a key public health problem due to their high rates of occurrence and intercurrence among this population, resulting in costs to the health service ${ }^{2}$.

The World Health Organization (WHO) conceptualizes falls as "an event that results in a person coming to rest inadvertently on the ground or floor or other lower level, excluding intentional changes of position to support themselves on furniture, walls or other objects." The organization reports that $28 \%$ to $35 \%$ of people over 65 years of age suffer falls each year, with this proportion increasing to $32 \%$ to $42 \%$ among those aged over 70 years 3 .

The risk of falls is pertinent to the entire population. Among the elderly, however, it has a more significant meaning, as such events "can lead to incapacity, injury and death", thus generating psychological, social and economic costs, directly resulting in the reduced autonomy of the elderly ${ }^{4}$. Brazilian ${ }^{5,6}$ and non-Brazilian ${ }^{7,8}$ studies cite falls as one of the significant causes of mortality, morbidity and disability among the elderly population.

The relationship of death and falls and elderly persons is a highly relevant topic, as the mortality of the elderly in health services has not yet been satisfactorily recorded, either due to under-informing or under reporting. The initial cause of the process of morbidity, namely the fall itself, is often neglected, and the diseases resulting from falls or hospitalization, such as infections, after the elderly person enters the health service, are prioritized ${ }^{9}$.

Under-informing consists of the incorrect completion of death certificates. This fact arises from a lack of knowledge among professionals responsible for the proper completion of the Death Certificate (DC) and the importance of this document as a source of health data. Underreporting, meanwhile, consists of not reporting deaths to the Mortality Information System (MIS), a frequent problem in the north, northeast and central-west regions ${ }^{9}$ of Brazil. Thus, under-informing and underreporting can mask the true scale of the disease, omitting death rates due to falls and hindering the planning of public health policies ${ }^{10}$.

Due to the importance attributed to studies that focus on the health of the elderly, especially those seeking strategies to improve the quality of life of this population, there is a clear need for researchers to focus their work on new ways of caring for the elderly. The state of the art on this subject may therefore benefit from bibliometric studies.

Bibliometrics is formed of a group of laws and empirical principles derived from the science of information, whose primary purpose is to explore the quantitative aspects of findings from literature, dissipate available and recorded information, and identify the most prolific research areas, researchers, periodicals and institutions in a certain theme or related areas, as well as frequently cited works ${ }^{11}$.

Moura et $\mathrm{al}^{12}$ state that the analysis of citations allows the measuring of the repercussion and visibility of certain authors, which institutions are most active in the subject and which is the most frequently used source of information, or in other words, provide a mapping of a certain area of knowledge and identify consolidated theories and methodologies.

In the present article, bibliometric research was applied to answer the following question: what is the scientific production regarding the association between fallsand death among elderly people?

By answering this question through the use of bibliometric metrics, the objective was to map the 
international scientific production on falls and deaths among elderly persons.

\section{METHOD}

An exploratory and descriptive bibliometric study was performed. This data collection and analysis technique has been identified as an argumentative source in the battle for research investment resources, academic rankings and as a basis for choosing scientific productions ona theme ${ }^{13}$.

The steps for the analysis performed here follow three procedures: the definition of the database to be consulted and the criteria to be used for collection; the collection of data; and the representation and analysis of the same ${ }^{14}$.

The ISI Web of Knowledge/Web of Science database was selected due to its "academic recognition as one of the most comprehensive databases of journals covering several areas of scientific knowledge", and its important and pioneering role in bringing together journals from more than 100 areas of knowledge ${ }^{12}$.

For data collection, carried out between July and August 2017, the search period was established as the complete years covered by the database (19452016), in order to allow the replication or updating of this study without the need to start again from the beginning.

The descriptors were defined from the Descriptors in Health Sciences (DeCS) catalog, with the following search terms selected: "elderly*", "fall*" and "death*". Other commonly used terms, such as "older" or "frail", were not included in the search terms as they are synonyms for "elderly" within the DeCS library. The quotation marks indicate the exact representation of terms with more than one word and the asterisks identify the inclusion of plurals. These terms represent the intended combinations used for the purpose of the study.

Data collection was performed by searching for these terms in the "topic" area, which represents the titles, abstracts, author's keywords and keywords created (keywords plus) of articles.
After the search, the works found were refined through the application of the filters provided by the database search engine. No refinement filter was applied for the areas of knowledge, countries or languages of the studies, and so all records of publications that had a combination of the three terms were included. Articles from events or considered to be in the editing process (conference proceedings), records arising from proceedings papers, editorial material and letters were excluded from the results, resulting in the inclusion of final and complete articles and reviews only. A total of 668 studies were thus identified, which were used as the set of articles for the bibliometric analysis proposed in this article.

The material was then analyzed by exporting the data into the HistCite ${ }^{\mathrm{TM}}$ bibliometric analysis software package in order to organize the information and facilitate analysis. The following items were analyzed: the trajectory of the annual evolution of publications; the journals with the greatest number of records; the authors with the most publications; and the number of articles distributed by author's country of origin. In addition to these data generated by the software, the ten articles most cited globally and the ten most cited articles locally were elucidated in order to identify their main contributions to the subject of falls and death among elderly persons.

As this was a bibliometric study, it was not required to be submitted to the Ethics Committee For Research Involving Human Beings. However, the researchers committed to maintaining the ethical principles advocated for research of this nature, respecting the ideas and citations and referencing the authors and their publications.

\section{RESULTS}

The search conducted for the period from 1945 to 2016 identified the first article as appearing in 1990. The results evaluated therefore covered the period from 1990 to 2016.

Following the bibliometric survey, 668 articles were identified that included the descriptors related to the study within their scope. These articles 
were published in 364 different journals indexed to the database in question and written by 2,958 authors linked to 1,131 research institutions located in 63 countries. These articles employed 22,093 references, with an average of approximately 33 references per article.

The evolution of scientific production in the field of study of falls and death among the elderly is shown in Figure 1, which shows the annual number of publications in the period studied. It is notable that international interest on the subject began in the nineties and has increased since this period, with some peaks and troughs over time.
In order to identify the most heavily represented international journals in the area of research on falls and death in the elderly, the 364 journals were analyzed based on the number of articles published on the subject and the total number of citations.

Table 1 shows the list of the most representative journals in terms of the number of publications on the topic under study. The relationship between the number of citations and the number of articles published in each of the journals can also be seen, providing initial information on the impact of articles identified in these journals through the total number of citations received.

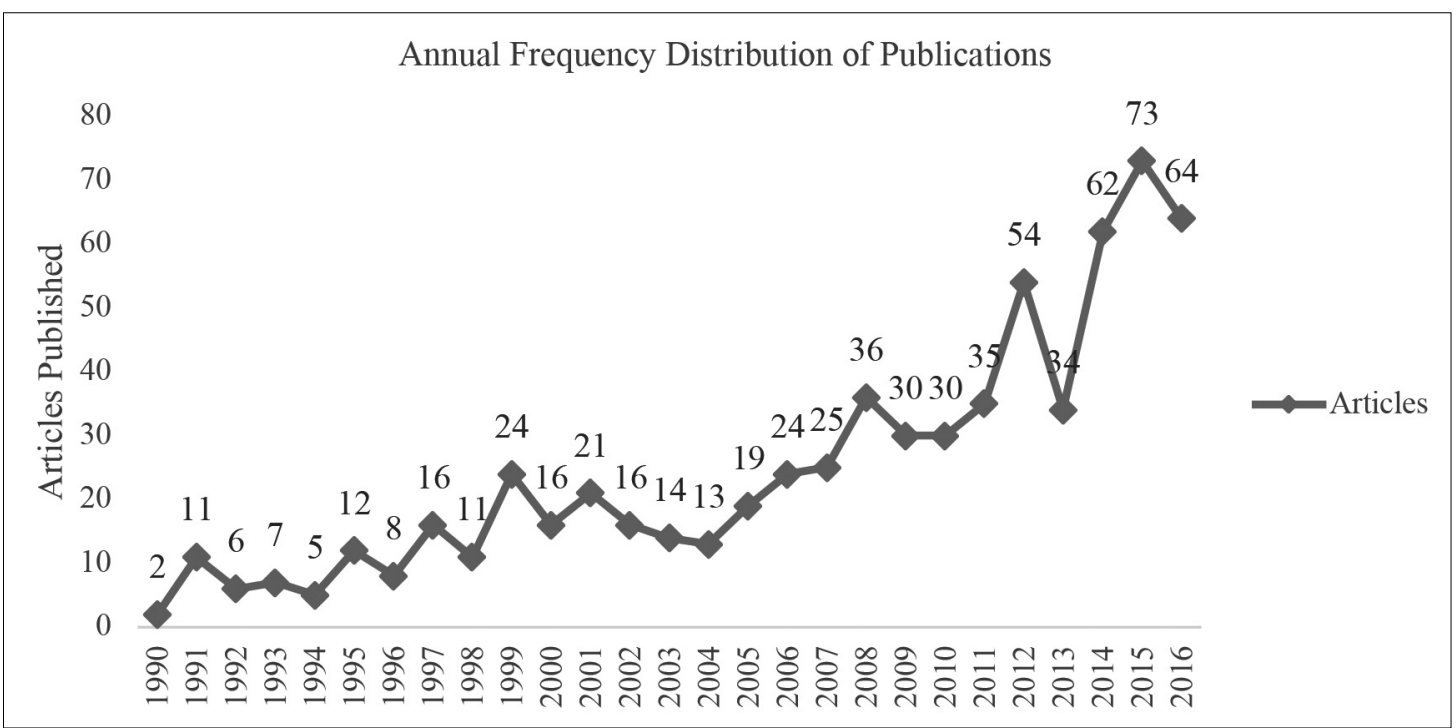

Source: Web of Science, 2017.

Figure 1. Distribution of publications on falls and deaths among the elderly from 1990 to 2016. 
Table 1. Top Ten Journals with most articles published between1990and2016in the Web Of Science database (2017).

\begin{tabular}{llll}
\hline Journals & $\begin{array}{l}\text { Quantity of } \\
\text { articles }\end{array}$ & Citations & $\begin{array}{l}\text { Citations/ } \\
\text { Quantity }\end{array}$ \\
\hline Journal of the American Geriatrics Society & 24 & 1,373 & 57.21 \\
Injury-International Journal of the Care of the Injured & 17 & 242 & 14.24 \\
Age and Ageing & 14 & 506 & 36.14 \\
Archives of Gerontology and Geriatrics & 13 & 182 & 14.00 \\
Plos One & 12 & 80 & 6.67 \\
Journals of Gerontology Series A-Biological Sciences and Medical Sciences & 10 & 4,378 & 437.80 \\
Aging Clinical and Experimental Research & 9 & 65 & 7.20 \\
Drugs \& Aging & 9 & 405 & 45.00 \\
European Journal of Epidemiology & 9 & 103 & 11.45 \\
Journal of Trauma-Injury Infection and Critical Care & 9 & 410 & 45.56 \\
\hline Total & 126 & 7,744 & - \\
\hline
\end{tabular}

The authors with the most publications on the subject, their institutional links and the country of origin of the institution were then identified. Among the authors with the most publications on the subject in the Web of Science database are Krannus P. with ten publications, Parkkari J. with eight and Palvanen M. with seven. These authors are all from the University of Tampere in Finland.

The most representative countries, with most of the scientific production in the field studied, were Australia, Canada, Finland, the UK and the USA. Although the USA has the greatest number of publications, with 233 articles, representing 35\% of the published works, Finland, with only 19 articles (3\% of the total), is home to the institution linked to the most frequently cited authors.

The classification of scientific studies by the number of citations received reveals the works that are considered the fundamental basis for the subject. While it takes some time for articles to begin to be cited by other researchers, the evaluation of the citations in the present study sought to establish the state of the art in the area of research on falls and deaths among the elderly, based on articles with titles that include the terms used in the searches and indexed in one of the previously identified journals with the highest number of citations on the subject.
With these criteria, ten articles were selected, which were analyzed with the Historiograph/ HistCite tool, through which it was possible to identify articles that are related to one other, mainly through the references used and/or cited (Figure 2), where each "circle" represents an article, the number of which identifies the work (author(s), year); each "arrow" shows the links between the articles, and the direction of the arrows indicates the relationship between the work and the study that later cites it; the "GCS" side represents the Global Citation Score of the Top Ten articles on the topic which received the greatest amount of citations in the Web of Science ${ }^{T M}$; and the "LCS" side represents the Local Citations Score of the ten articles on the topic that received the greatest number of citations of the selected articles. This graphic representation allowed the time line and main articles of the studied subject to be defined.

Within the GCS, the first article cited, the study by Abraira et al. (1) ${ }^{15}$, was not included in the discussion of this study as the keyword "fall" does not refer to an accident as described by the $\mathrm{WHO}^{3}$, but to a drop in glycohemoglobin levels. The studies by Staessen et al. $(2)^{16}$, Keatinge et al. (3) ${ }^{17}$, Kario et al. (6) ${ }^{20}$ and Duncan et al. (9) ${ }^{23}$, also described falls as something other than a physical accident, and were therefore not included in the present study. 


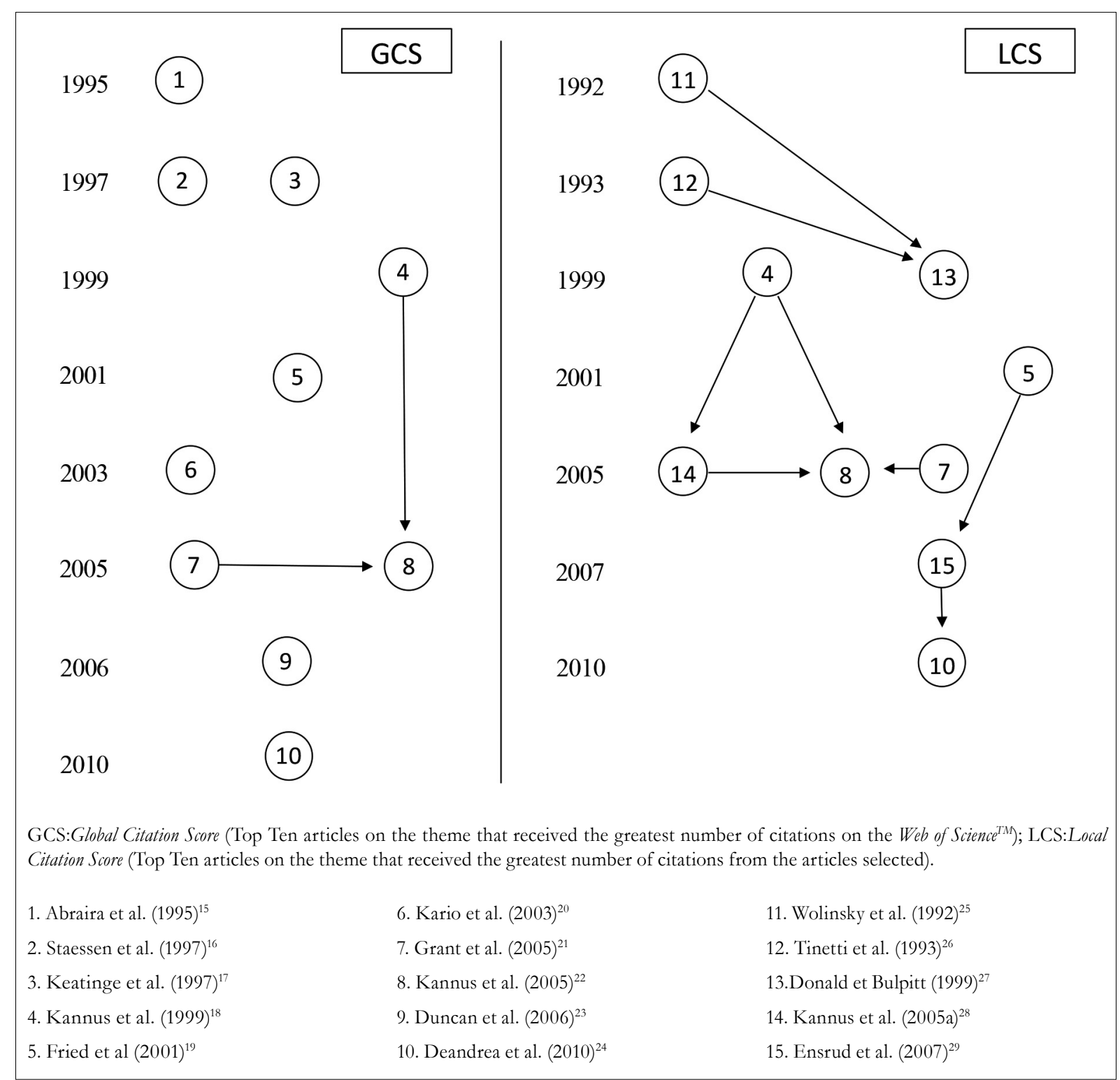

Figure 2. Top Tenmost cited articles on Web of Science ${ }^{\mathrm{TM}}$ (Global Citation Score) and Top Tenmost cited articles in the group of selected articles (Local Citation Score) within the selected group.

\section{DISCUSSION}

The results of the present bibliometric review identified few articles on the subject of death due to falls among elderly persons in the Web of Science database.

In terms of the evolution of scientific production, Figure 1 shows that the number of articles published remained low during the first half of the 2000 s, with a slight peak in 1999, most likely because this year was proclaimed the International Year of the Elderly by the United Nations, which may have increased interest in research in this area of study. Production increased slightly from 2005 onwards, with the small decline in 2016 reflecting the fact that the databases or indexations for this year were incomplete at the time of collection of this study.

The trend line of the subject shows a discrete increase in the number of publications, indicating that there is renewed interest among the international 
scientific community in disseminating knowledge from this field of study, while gaps to be addressed in the topic of study remain.

The ten most cited journals (Table 1) comprised approximately $19 \%$ of the total articles retrieved. The Journal of the American Geriatrics Society had the largest number of publications, with approximately $4 \%$ of the total articles, but the Journals of Gerontology Series A-Biological Sciences and Medical Sciences had ten publications and 4,378 citations, considerably increasing its impact factor in the subject studied, since the amount of citations a journal obtains can serve as an indicator of the relevance of the works.

With regard to the most representative authors and institutions in this subject, the most cited authors were linked to only seven universities in five countries, most notably the University of Tampere in Finland, with 31 publications, approximately $5 \%$ of the papers. This represents a share greater than the sum of articles of the other countries combined, identifying Finland as a leading nation in research on falls and deaths in the elderly.

The list does not include Brazilian researchers, or researchers linked to Brazilian institutions, revealing the scarcity of publications on the subject in journals indexed by the Web of Science from this country, and indicating a gap in its knowledge base.

The relationship between the articles in Figure 2 revealed numbers $(4)^{18}$ and $(7)^{21}$ to be considered "authority articles" or "base articles" which are the main references for other authors and the subject of the greatest number of citations ${ }^{14,30}$

In addition to the authority articles, there are also "hub" or "connection" articles ${ }^{14}$, which condense important information from previous works, connecting them with more recent studies, and which are frequently cited, identified by numbers $(8)^{22},(10)^{24}$, $(13)^{27}$ and $(15)^{29}$.

The first study on the proposed theme was found in 1999 in the form of the publication by Kannus et al. (4) ${ }^{25}$, which was considered both a global and a local authority article in the relationship shown in Figure 2. This study verified lesions and death-induced deaths among older adults in a white population aged over 50 years in Finland from 1970 to 1995 . It found that the number of fallsinduced deaths increased considerably over the years studied, with an overall increase of $136 \%$, and concluded that the number of elderly persons with fall-induced injuries increased at a rate that cannot be explained simply by demographic changes. This study suggested the adoption of large-scale preventive measures to control the increase of these lesions, recommendations that were reinforced by later studies ${ }^{2,31,32}$.

The study by Grant et al. (7) ${ }^{26}$ evaluated whether the consumption of supplements such as vitamin D and calcium could prevent low trauma secondary fractures. The results showed that there was no difference in fracture incidence, number of falls or quality of life, concluding that oral supplementation is not a protective factor against fractures among the elderly. This is a subject that deserves further evaluation, since there are studies that indicate that the use of supplements is a protective factor ${ }^{33,28}$, while others have found no impact through the use of these supplements ${ }^{34}$.

Of the Hub articles, the first study with a major impact was that of Kannus et al. $(8)^{28}$ which analyzed the effectiveness of prevention when reducing the risk of falls of the elderly person. The study found that there are prevention programs, such as regular exercises; vitamin $\mathrm{D}$ and/or calcium supplementation; suspension of psychotropics; ocular surgeries; evaluation and professional modification of environmental risks; hip protectors and multifactorial preventive programs to evaluate and reduce many of the predisposed and situational risk factors both at home and in hospitals and long-term institutions, similar to thereview study by Falsarella et $\mathrm{al}^{33}$. The study by Kannus et al $^{32}$ also contributed to the identification of gaps in the implementation of these programs aimed at the elderly, thus demonstrating the importance of new research for the scientific environment.

In Hub article No. $13^{27}$, the authors carried out a study that aimed to determine results among elderly persons who fell once or more than once in their homes, indicating a stronger relationship between 
individuals who suffered falls and admission to longterm care facilities than the between falls and death, results corroborated by the study of Souza et al ${ }^{35}$, where institutionalized elderly people were found to be at a greater risk of falls than those living in the community, reinforcing family and domestic support as a vitally important factor for the quality of life of the elderly person.

Ensrud et a ${ }^{19}$, in study No. 15, found a standard frailty phenotype associated with the risk of falls, fractures and mortality in elderly women, following a cohort of 6,724 women over 68 years of age; and concluded that frail women were at increased risk of recurrent falls, various fractures and death. Similar results were found in the Nascimento and Tavares study ${ }^{2}$, indicating that the frailty of an elderly person is an important predisposing factor to falls.

Study No.10 by Deandrea et $\mathrm{al}^{24}$ investigated risk factors for falls among elderly people living in the community, namely history of falls; gait problems; use of walking aids; vertigo; Parkinson's disease and the use of psychotropic drugs, with a higher risk of recurrent falls. Rodrigues et $\mathrm{l}^{36}$ found similar factors in a study carried out in 2014.

The present study has some limitations, one of which is the use of a single database, the Web Of Science, for analysis. Another limitation relates to the use of the descriptor "fall", which identified results not only for the fall as a physical accident, but for falls of rates, among other factors, which hindered the evaluation of the final results.
It is important to consider that there are few findings in literature that address this problem as a factor with social and professional impact, as there is a need to consider old age as an important aspect of life and the locus of new health policies, as this population continues to grow and demands specific products and services.

\section{CONCLUSION}

The present study carried out a bibliometric mapping of international scientific evidence about falls and deaths among the elderly in the ISI Web of Knowledge/Web of Science database, allowing the identification of bibliometric indicators to characterize the state of the art related to the subject and presenting the relevant works on the subject, periodicals, countries and the authors with the greatest number of publications and citations.

Because it is a specific population, there is a need to discuss this issue in the training of health professionals, as it constitutes a possibility for reviewing lifelong concepts and for avoiding falls, so improving the quality of life of this population.

The present study also found that there are gaps and research opportunities to be explored, in addition to conflicting results, and recommends further studies that compare the results presented in this work in international and national databases, as well as investigating the representativeness and profile of publications of Brazilian authors, which were not identified in this bibliometric analysis.

\section{REFERENCES}

1. Küchemann BA. Envelhecimento populacional, cuidado e cidadania: velhos dilemas e novos desafios. Soc Estado. 2012;27(1):165-80.

2. Nascimento JS, Tavares DMS. Prevalência e fatores associados a quedas em idosos. Texto Contexto Enferm. 2016;25(2):1-9.

3. Organização Mundial da Saúde. WHO Global Report on falls prevention in older age. Unided States of America: WHO; 2007.

4. Terra NL. Entendendo as síndromes geriátricas. Rio Grande do Sul: EDIPUCRS; 2013.
5. Rosa TSM, Moraes AB, Peripolli A, Santos Filha VAV. Perfil epidemiológico de idosos que foram a óbito por queda no Rio Grande do Sul. Rev Bras Geriatr Gerontol. 2015;18(1):59-69.

6. Oliveira AS, Trevizan PF, Bestetti MLT, Melo RC. Fatores ambientais e risco de quedas em idosos: revisão sistemática. Rev Bras Geriatr Gerontol. 2014;17(3):637-64.

7. Larson LM, Sliter R, Helmer SD, Reyes J, Crawford $G$, Haan JM. Outcomes in elderly fall victims: what happens after hospital discharge? J Surg. 2016;212(6):1106-14. 
8. Nilsson M, Eriksson J, Larsson B, Oden A, Johansson $\mathrm{H}$, Lorentzon M. Fall risk assessment predicts fallrelated injury, hip fracture, and head injury in older adults. J Am Geriatr Soc. 2016;64(11):2242-50.

9. Messias KLM, Bispo Júnior JP, Pegado MFQ, Oliveira LC, Peixoto TG, Sales MAC, et al. Qualidade da informação dos óbitos por causas externas em Fortaleza, Ceará, Brasil. Ciênc Saúde Coletiva. 2016;21(4):1255-67.

10. Justino JR, Freire FHMA, Lúcio PS. Estimação de sub-registros de óbitos em pequenas áreas com os métodos bayesiano empírico e algoritmo EM. Rev Bras Estud Popul. 2012;29(1):87-100.

11. Lopes S, Costa MT, Fernández-Llimós F, Amante MJ, Lopes PF. A Bibliometria e a avaliação da produção científica: indicadores e ferramentas. Actas Congr Nac bibliot, Arquiv Doc. 2012;11:1-7.

12. Moura LKB, Mesquita RF, Mobin M, Matos FTC, Monte TL, Lago EC, et al. Uses of bibliometric techniques in public health research [abstract]. Iran J Public Health. 2017;46(10):1435-6.

13. Diem A, Wolter S. The Use of bibliometrics to measure research performance in education sciences. Res High Educ. 2012;54:86-114.

14. Santos PM, Selig PM. Indicadores para o novo serviço público: uma análise bibliométrica e sistêmica. Perspect Ciênc Inf. 2014;19(3):82-97.

15. Abraira C, Colwell JA, Nuttall FQ, Sawin CT, Nagel NJ, Comstock J, et al. Veterans Affairs Cooperative Study on glycemic control and complications in type II diabetes (VA CSDM): results of the feasibility trial. Diabetes care. 1995;18(8):1113-23.

16. Staessen JA, Fagard R, Thijs L, Celis H, Arabidze GG, Birkenhäger WH, et al. Randomised doubleblind comparison of placebo and active treatment for older patients with isolated systolic hypertension. Lancet. 1997;350(13):757-64.

17. Keatinge WR, Donaldson GC. Cold exposure and winter mortality from ischaemic heart disease, cerebrovascular disease, respiratory disease, and all causes in warm and cold regions of Europe. Lancet. 1997;349(10):1341-6.

18. Kannus P, Parkkari J, Koskinen S, Niemi S, Palvanen M, Järvinen M, et al. Fall-induced injuries and deaths among older adults. JAMA. 1999;281(20):1895-9.

19. Fried LP, Tangen CM, Walston J, Newman AB, Hirsch C, Gottdiener J, et al. Frailty in older adults: evidence for a phenotype. J Gerontol Ser A Biol Sci Med Sci. 2001;56(3):146-56.
20. Kario K, Pickering TG, Umeda Y, Hoshide S, Hoshide Y, Morinari M, et al. Morning surge in blood pressure as a predictor of silent and clinical cerebrovascular disease in elderly hypertensives. Circulation. 2003;107(10):1401-6.

21. Grant AM, Avenell A, Campbell MK, McDonald AM, MacLennan GS, McPherson GC, et al. Oral vitamin D3 and calcium for secondary prevention of low-trauma fractures in elderly people (Randomised Evaluation of Calcium Or vitamin D, RECORD): a randomised placebo-controlled trial. Lancet. 2005;365:1621-8.

22. Kannus P, Sievänen H, Palvanen M, Järvinen T, Parkkari J. Prevention of falls and consequent injuries in elderly people. Lancet. 2005;366(9500):1885-93.

23. Duncan JS, Sander JW, Sisodiya SM, Walker MC. Adult epilepsy. Lancet. 2006;367(9516):1087-1100.

24. Deandrea S, Lucenteforte E, Bravi F, Foschi R, Vecchia CL, Negria E. Risk factors for falls in community-dwelling older people: A systematic review and meta-analysis. Epidemiology. 2010;21(5):658-68.

25. Wolinsky FD, Johnson RJ, Fitzgerald JF. Falling, health status, and the use of health services by older adults: A prospective study. Med Care. 1992;30(7):587-97.

26. Tinetti ME, Liu WL, Claus EB. Predictors and prognosis of inability to get up after falls among elderly persons. JAMA. 1993;269(1):65-70.

27. Donald IP, Bulpitt CJ. The prognosis of falls in elderly people living at home. Age Ageing. 1999;28(2):121-5.

28. Kannus P, Sievänen H, Palvanen M, Järvinen T, Parkkari J. Fall-induced deaths among elderly people. Am J Public Health 2005;95(3):422-4.

29. Ensrud KE, Ewing SK, Taylor BC, Fink HA, Stone KL, Cauley JA, et al. Frailty and risk of falls, fracture, and mortality in older women: The Study of Osteoporotic Fractures. J Gerontol Ser A Biol Sci Med Sci. 2007;62(7):744-51.

30. Santos SM, Souza WV. Introdução à estatística espacial para a saúde pública. Brasília, DF: Ministério da Saúde; 2007.

31. Araújo AM, Menezes RMP, Mendonça AEO, Lopes MS, Tavares AM, Lima HCF. Perfil da mortalidade por quedas em idosos. Rev Pesqui Cuid Fundam. 2014;6(3):863-75.

32. Ambrose AF, Paul G, Hausdorff JM. Risk factors for falls among older adults: A review of the literature. Maturitas. 2013;75(1):51-61. 
33. Falsarella GR, Gasparotto LPR, Coimbra AMV. Quedas: conceitos, frequências e aplicações à assistência ao idoso. Revisão da literatura. Rev Bras Geriatr Gerontol. 2014;17(4):897-910.

34. Uusi-Rasi K, Patil R, Karinkanta S, Kannus P, Tokola $\mathrm{K}$, Lamberg-Allardt C, et al. Exercise and vitamin D in fall prevention among older women: a randomized clinical trial. JAMA Intern Med. 2015;175(5):703-11.
35. Souza CC, Valmorbida LA, Oliveira JP, Borsatto AC, Lorenzini M, Knorst MR, et al. Mobilidade funcional em idosos institucionalizados e não institucionalizados. Rev Bras Geriatr Gerontol. 2013;16(2):285-93.

36. Rodrigues IG, Fraga GP, Barros MBA. Falls among the elderly: risk factors in a population-based study. Rev Bras Epidemiol. 2014;17(3):705-18.

Received: October 30, 2017

Reviewed: March 13, 2018

Accepted: May 01, 2018 